\title{
Responsabilidad Social: Dimensión sustentable hacia el ambiente de las empresas carboníferas en Colombia y Venezuela
}

Social Responsibility:
Sustainable dimension towards the environment
of coal companies in Colombia and Venezuela

DOI: http://dx.doi.org/10.17981/econcuc.40.1.2019.03

Artículo de revisión. Fecha de recepción: 14/10/2018 Fecha de aceptación: 25/02/2019

Leandro Amiro Sierra Daza

Escuela de Minería de La Guajira. (Riohacha, Colombia)

escuelamineria@gmail.com

Annherys Isabel Paz Marcano

Universidad de La Guajira. (Riohacha, Colombia) aipaz@uniguajira.edu.co

Danny Daniel López Juvinao

Universidad de La Guajira. (Riohacha, Colombia)

dlopezj@uniguajira.edu.co

Para citar este artículo:

Sierra, L., Paz, A. y López D. (2019). Responsabilidad social: Dimensión sustentable hacia el ambiente en empresas carboníferas de Colombia y Venezuela. Económicas CUC, 40(1). 47-60. DOI: http://doi.org/10.17981/econcuc.40.1.2019.03

\section{Resumen}

En un nuevo escenario globalizado y cambiante que obliga a las organizaciones a transformar sus estructuras, para aportar más allá de su simple razón de ser, la responsabilidad social empresarial resulta ser una respuesta efectiva para cualquier tipo de organización ya que permite lograr los propósitos misionales sin menos cabo de esas exigencias adicionales. Así, se presenta este artículo cuyo objetivo es analizar la responsabilidad social como una dimensión sustentable hacia el ambiente en empresas carboníferas de Colombia y Venezuela. La investigación fue de tipo analítica y descriptiva, utilizando la técnica de revisión documental para a través de la consulta de fuentes impresas y electrónicas. Se evidenció como las empresas carboníferas en Colombia y Venezuela promueven la responsabilidad social mediante la gestión de sus procesos de trabajo con un sentido de compromiso hacia el desarrollo sustentable, donde no es suficiente con la práctica de actividades sociales, sino se ejerce la responsabilidad con ellas, su gente y el ambiente, para generar un compromiso social y ambiental, compartido con los grupos de interés desde los principios ético promovidos en su razón de ser; además, del fomento de la participación voluntaria, a fin de impulsar el bienestar del colectivo social en el entorno, en pro de la construcción de sociedades sanas. Se concluye que el éxito de las actividades empresariales del sector carbonífero de Colombia y Venezuela, se traduce en la interrelación con los grupos de interés enlazando la participación del capital humano como eje motor en la generación de ideas y alternativas viables para fomentar la responsabilidad social y ambiental, y con ello la sustentabilidad.

Palabras Clave: Responsabilidad social; desarrollo sustentable; bienestar del colectivo social; empresas carboníferas.

\section{Abstract}

In a new globalized and changing scenario that forces organizations to transform their structures, to contribute beyond their simple reason for being, corporate social responsibility turns out to be an effective response for any type of organization since it allows achieving missionary purposes without less out of those additional demands. Thus, this article is presented whose objective is to analyze social responsibility as a sustainable dimension towards the environment in coal companies in Colombia and Venezuela. The research was analytical and descriptive, using the documentary review technique to consult printed and electronic sources. It was evident how the coal companies in Colombia and Venezuela promote social responsibility by managing their work processes with a sense of commitment to sustainable development, where it is not enough to practice social activities, but rather to exercise responsibility with them, their people and the environment, to generate a social and environmental commitment, shared with interest groups based on the ethical principles promoted in their reason for being; in addition, the promotion of voluntary participation, in order to promote the welfare of the social group in the environment, in favor of building healthy societies. It is concluded that the success of the business activities of the coal sector in Colombia and Venezuela, translates into the interrelation with the interest groups linking the participation of human capital as a driving force in the generation of ideas and viable alternatives to promote social and environmental responsibility, and with it sustainability.

Keywords: Social responsibility, sustainable development, welfare of the social collective, coal companies. 


\section{INTRODUCCIÓN}

En la actualidad las empresas que integran la dinámica económica a escala mundial, sean estas de carácter público o privada, o de diversos sectores de la producción, extracción o transformación, sin exclusión del Carbonífero en Colombia y Venezuela, se encuentran inmersas en una estructura de cambios constantes, donde requieren para su supervivencia emplear acciones estratégicas como mecanismo de respuesta, capaz de atender las necesidades del entorno en el cual se disponen sus bienes y servicios, es decir, es un nuevo escenario globalizado obligando a las organizaciones el transformarse, adaptarse y desempeñar nuevos roles sociales para garantizar mayor perdurabilidad en el tiempo (Chumaceiro, Hernández y Chirinos, 2016).

En este sentido, hoy en día, las referidas empresas para mantener la confianza, reputación y credibilidad en los mercados, no solo deben focalizarse en el alcance de la sustentabilidad económica como parte de la eficacia para obtener la productividad según el resultado de sus procesos de trabajo, sino también en la sustentabilidad social y ambiental, donde de manera integral deben aportar bienestar en su entorno en pro de comunidades sanas y con ello construir el bien común.

Para Soto y Cárdenas (2007) orientar hacia el bienestar común, implica direccionar hacia empresas éticamente responsables, teniendo un mismo objetivo, pero además estimulando a las personas y a ellas mismas a ir más allá de sus fines particulares, buscando lo que es bueno para el conjunto de la sociedad.

Si bien es cierto, las empresas independientemente de su razón social, están llamadas a ejercer un voluntariado respon- sable estimulando la participación activa de su gente con el entorno, además del intercambio de responsabilidades con los grupos de interés, para gestar un compromiso compartido frente a la responsabilidad social y ambiental. Expone Guédez (2008) como la responsabilidad sugiere responder por lo que hacemos, dejamos de hacer o dejamos hacer, además de rendir cuentas por lo que se hizo respecto a las obligaciones y compromisos.

Dentro de este particular, para efecto de construir un sentido responsable en las empresas carboníferas colombianas y venezolanas, promoviendo el bienestar común con el entorno de manera sustentable, resulta imprescindible e ineludible promover una cultura social, entre empleados, grupos de interés y viceversa, representando un marco simbiótico "ganar-ganar" para la edificación de organizaciones con sentido de compromiso social hacia el entorno. Según, Harris, Paz y Franco (2014) quienes gerencian tiene esta responsabilidad de fomentar el compromiso compartido empresa-sociedad.

La responsabilidad social lleva consigo un comportamiento tanto interno como externo, pudiendo desde la gestión de sus procesos de trabajo fomentar el desarrollo sustentable, es decir, crear un valor corresponsable con la dimensión social y ambiental, mediante la práctica de principios éticos y sociales, insertos en su razón de ser, generando con ello ventajas competitivas en el sector productivo donde se desenvuelven. De este modo, para Pizzolante (2010), la sustentabilidad empresarial es el puente que permite pasar la visión tradicional de la acción en sociedad y la llamada responsabilidad social, a la consciencia en el liderazgo de construir empresas socialmente responsables, dependiendo cada vez mas de aquellas 
empresas que comunican a través de su actuación su capacidad de influir positivamente en el entorno donde opera.

Se infiere que la responsabilidad social en las empresas, sin excluir el sector carbonífero de Colombia y Venezuela, conlleva la gestión de actividades de trabajo hacia la consecución de una dimensión sustentable ante el ambiente, donde se oriente la acción comprometida de sus colaboradores internos y externos, convirtiéndose en un instrumento gestor y ejecutor del bienestar colectivo, es decir, generador de progreso que permite al individuo sentirse parte en la construcción de un proyecto de calidad de vida, aunado a velar por un ambiente sano y equilibrado por un desarrollo sustentable para él, los suyos y sus conciudadanos.

Según Añez, Hernández, Silvestri y Gómez (2008), la responsabilidad social es una estrategia corporativa que implica el compromiso de las empresas, a través de la aplicación sistemática de recursos, para respetar, promover el derecho de las personas, el crecimiento de la sociedad y el cuidado del ambiente. Mientras, para Castro, Hernández y Bedoya (2016), la responsabilidad social es una actitud consciente, que nace de una inspiración voluntaria, basada en el reconocimiento y aceptación de los compromisos con la sociedad, representando una actitud proactiva permitiendo la adopción de hábitos, destrezas y procesos con el fin de disminuir las repercusiones negativas que impactan al ambiente y la sociedad.

No obstante, Blanco-Uribe (2005) plantea considerar al ambiente incluyendo los aspectos naturales, desde un sentido estricto con interacciones entre él y el ser humano, donde se incorporan aspectos culturales vinculantes a la calidad de vida, en los medios o hábitats tanto urbanos como rurales. Por otra parte, Garmendia, Salvador, Crespo y Garmendia (2010) expresan al ambiente como el conjunto de circunstancias físicas, culturales, económicas y sociales, entre otras, que rodean a la persona.

En virtud de los aspectos analizados y con ello el abordaje del tema ambiental, resulta complejo mencionar acerca del desarrollo sustentable y más aun si a ello se le inserta la dimensión social, la cual en las últimas décadas, se ha convertido en un argumento inexcusable de tratar en convocatorias de negocios a escala mundial, en congresos, simposios y talleres, entre otros; han sido espacios de protagonismo sobre la realidad de la aplicación y seguimiento de la responsabilidad social y el marco ambiental por parte de las empresas, constituyendo estas premisas el foco de atención de expertos al formular tratados, asi como el cumplimiento en indicadores de gestión empresarial. Al respecto Mendoza-Fernández, SalasSolano y López-Juvinao (2015) promueven iniciativas de responsabilidad social dirigidas hacia dentro y hacia afuera, las cuales deben ser sostenibles e integradas a la institución.

En este particular, se argumenta como en la última década se ha observado el interés de estudiar el tema de la responsabilidad social y sustentabilidad ambiental tanto en Venezuela como en Colombia, especialmente en trabajos de especialización como los de Moncada (2016), Daza y Pinero (2017), Añez et al. (2008), Ostau y Niño (2012), Solano (2014), Pertuz (2016), Paz, Paz y Paz (2011), Paz, Harris y Paz (2015), solo por nombrar algunos de las publicaciones, en los cual el tema de atención es la postura de los investigadores, sobre la aplicabilidad de la responsabilidad social con sostenibilidad ambiental en las 
actividades empresariales, pudiendo desde su gestión ganar ventajas competitivas, y propender sus acciones al bienestar y calidad de vida de su gente y comunidades adyacentes a ellas.

En este sentido y en vista de la importancia que ha tomado el tema en los últimos años, los indicadores de gestión empresarial deben incorporar lo relacionados a la gestión social, donde en el sector carbonífero de Colombia y Venezuela representan una referencia, para medir el comportamiento responsable de la funcionalidad del negocio con el entorno donde está asentada, estando asociada a las actividades voluntarias ante la comunidad, aplicando acciones dispuestas a velar por la calidad de vida, bienestar del colectivo, el ambiente sano y con ello el desarrollo sustentable; como plantean Paz, Harris y Franco (2016), la responsabilidad social se debe concebir como las repuestas voluntarias de las organizaciones a las necesidades o problemas surgidos de la sociedad.

En líneas generales, conocer el aporte ejercido por las empresas para coadyuvar el semiento de una sociedad sustentable, mediante la planificación y ejecución de proyectos, programas o planes de interés social donde incorporan a los distintos colaboradores y actores sociales, al desarrollo no solo humano sino también del colectivo, es parte de su quehacer consustancial con la sociedad; en lo cual estan de acuerdo a Paz, Núñez, Salom y Rosales (2013), por ser una actividad propia de la moralidad, pero ofrece valor agregado a la sociedad, la cual está siempre vigilante por la calidad de vida y el cumplimiento de la justicia en todos los órdenes.

En virtud de lo expuesto, las empresas Carboníferas de Colombia y Venezuela, se han comportado como agentes impulsores del cambio social, desde la atención cons- tante a las necesidades acuciantes de las comunidades, hasta el compromiso hacia la responsabilidad social, facilitando la edificación sustentable en pro del progreso social, esto lo han demostrado Daza y Pinedo (2017), quienes señalan a las empresas la obligación de ejecutar planes de desarrollo sostenible que incluyan a las minorías étnicas, dando la rendición de cuentas y la reparación del deterioro ambiental generado por la explotación de sus recursos naturales, sin embargo, los resultados en el contraste de las comunidades no han sido favorecedores.

De esta manera, se hace necesaria la incorporación de responsabilidad social en el plan estratégico de los negocios para así alcanzar ventajas competitivas, no solo desde el compromiso con la sociedad, sino como indicador, a través del ejercicio voluntario e implícito en la gestión social, para dimensionar su desempeño en las actividades productivas, como una fuente valorativa de la ética organizacional y con esto el valor corresponsable con su entorno.

Según Paz, Paz y Paz (2011) las empresas que obran en un modelo de negocio responsable promueven un compromiso compartido hacia la gestión de la responsabilidad social y ambiental, promoviendo ventajas competitivas en el mercado donde participan. En consecuencia a esto, deben presentar en el plan estratégico, como herramienta de apoyo administrativo y operativo para garantizar la práctica responsable hacia un desarrollo sustentable. En especial, por lo que señala Moncada (2016), las empresas del sector minero se han vuelto estratégicas para los países en función de los recursos que generan, y aunque en los países de Latinoamérica falte mucho por entender al respecto de la responsabilidad social, se está haciendo un esfuerzo al respecto. 
En líneas generales, se explica como la responsabilidad social representa un compromiso ético ante la toma de decisiones en la funcionalidad empresarial, capaz de generar un valor agregado a la sustentabilidad con el fomento de una cultura responsable al ambiente, es decir la formación de los colaboradores que coadyuden la interacción hombre-sociedadcapital, garantizando las necesidades sociales sin degradar las condiciones físico naturales del entorno, en todo caso ser garantes del bien común.

Para Garmendia, y Otros (2010) la sustentabilidad al ser criterio básico de la evaluación ambiental, a través de la aplicación de criterios de equidad entre la generación actual con la futura, de forma tal al desarrollo actual que no comprometa el desarrollo y la calidad de vida de las generaciones futuras. Por esto, de acuerdo a Paz et al. (2011) la responsabilidad social ha ganado espacio en las diversas empresas de la economía nacional, especialmente el sector carbonífero, constituyendo un indicador apuntando al compromiso demandante del desarrollo sustentable en la sociedad, el cual debe apoyarse en tres aspectos operantes del ser humano, pensar, sentir y actuar, no solo en la esfera cognitiva de quienes gestionan los procesos de trabajo, sino, en la fuerza laboral como parte de una sociedad éticamente responsable, con un sentido de deber compartido en la contribución voluntaria de ellas en aspectos legales, éticos y ambientales, para lo cual es necesario el cumplimiento de mecanismos estratégicos.

Desde esta óptica, este artículo tiene como propósito el análisis de la responsabilidad social como dimensión sustentable hacia el ambiente en empresas carboníferas de Colombia y Venezuela, represen- tado como un indicador para el fortalecimiento del compromiso ético y ambiental, capaz de atender las necesidades acuciantes del entorno, a fin de construir sociedades sanas y sustentables.

\section{Desarrollo}

\section{Responsabilidad Social: Modelo impulsor del desarrollosustentable}

En la actualidad, las empresas mineras en general han sido objeto de cambios, por lo cual han incorporado en sus estrategias de negocio la responsabilidad social, como destaca Solano (2014) al mostrar la labor realizada en el municipio de Tausa (Cundinamarca-Colombia); obligando a las empresas carboníferas a adaptarse a estos escenarios en escala mundial, siendo participes como agentes impulsores de bienestar del colectivo, concurriendo parte de su compromiso corresponsable con el entorno, direccionando para ello la práctica de mecanismos estratégicos que faciliten su capacidad de respuesta tanto económica como social en el entorno, al cual dispone la oferta de sus bienes y servicios.

En virtud de lo expuesto, vale acotar la actuación loable en la gestión de la responsabilidad social de las empresas carboníferas de Colombia y Venezuela, las cuales han ganado espacio, sin dejar a un lado el valor económico representativo como indicador para medir el compromiso de la demanda social, el cual se apoya en la gestión compartida con los grupos de interés internos y externos, mediante la práctica de actividades gestoras de una convivencia responsable, donde se generan dinamismos de trabajo de manera mancomunada, contribuyendo 
desde su desempeño a mejorar las condiciones de vida del colectivo social, pero al igual convirtiendo sus espacios en ejemplo de calidad de vida. Aunque, como señala Pertuz (2016), puede darse una minería responsable siempre y cuando se interiorice el concepto amplio de Responsabilidad Social Empresarial-RSE, y, por lo tanto, se cumpla con una serie de parámetros establecidos por los organismos internacionales.

En términos amplios, la responsabilidad social constituye una fuente distintiva para el alcance de ventajas competitivas en el sector carbonífero, siendo congruente con la construcción de un balance ético organizacional, donde las empresas como células de producción social deben comportarse como buenos ciudadanos corporativos, enmarcado su desempeño en un patrón voluntario, para la rendición de cuentas transparentes en pro del bien común desde los principios éticos, morales, disciplina, igualdad, respeto social y ambiental.

En otras palabras, las empresas no solo se deben preocupar por el desarrollo organizacional como resultado de su tejido económico, sino de la formación de sus colaboradores hacia una cultura de responsabilidad social y ambiental compartida, que agregue valor al desarrollo sustentable. Como dice Chiavenato (2017), la responsabilidad social es la actuación responsable de sus miembros, las actividades de beneficencia y los compromisos de la organización con la sociedad en general, de manera más intensa, con aquellos grupos o parte de la sociedad con que estés más en contacto.

Dentro de este contexto se infiere, que la responsabilidad social de las empresas carboníferas desde las dimensiones tanto internas como externas, debe fundar sus principios filosóficos de gestión bajo un sentido de compromiso social y ambiental para contribuir no solo al progreso sino al desarrollo sustentable. Y aunque se ha demostrado que falta mucho por hacer (Ostau y Niño, 2012; Pertuz, 2016; Moncada, 2016; Daza y Pinedo, 2017), se observa desde los países y las instituciones el apoyo de las iniciativas. Para Paz, Harris y Paz (2015) la responsabilidad social, rige la dimensión voluntaria de las acciones internas y externas, siendo la primera, el establecimiento de patrones en la calidad de vida de los colaboradores permitiendo satisfacer sus necesidades humanas; mientras la segunda es el carácter externo que se proyecta con el ejercicio del bienestar de las comunidades, a razón de la sostenibilidad socio-ambiental.

La práctica de la responsabilidad social actualmente representa un aporte voluntario al ejercido de las políticas gubernamentales, impulsadas durante los últimos años por los foros y conferencias en los que se alude al papel de los gobiernos en su desempeño, donde además aparecen continuamente discusiones sobre lo voluntario y/u obligatorio de la adopción de políticas formales RSE en los estados (Chumaceiro y Hernández, 2016). De tal manera entonces, estas acciones estratégicas compartidas, para el aseguramiento y competitividad de hechos valorativos de la acción social y de igual modo el capital natural, o intercambio de ideas y comportamientos integradores en valores tanto ético sociales como ambientales, promueven desde la gestión del negocio interno el desarrollo sustentable, mediante acciones para preservar la biodiversidad, con un sentido de responsabilidad ambiental.

De acuerdo a Claros (2001), el desarrollo sustentable es la combinación entre el crecimiento económico y la protección 
ambiental, ayudando a circunscribir el pensamiento del desarrollo sustentable y sostenible, cuyo fin esencial se orienta a generar una racionalidad eficiente y equitativa utilización de los recursos naturales, protejiendo y conservando el patrimonio ambiental de la humanidad.

Por otra parte, la responsabilidad social debe conjugar acciones que coadyuven el cuidado y preservación del capital natural desde la práctica de principios direccionados a velar por la corresponsabilidad ambiental, pero que en todo caso puedan plantear procesos de trabajo encausados en principios de ecoefiencia como fuente valorativa de la responsabilidad ambiental involucrando a los grupos de interés. Por esto (Gardetti, 2004), la responsabilidad ambiental posee un basamento ético y operativo, fundamentado en la ética de reciprocidad y compromiso (intergeneracional), impulsado en una forma distinta de gestionar, producir, consumir y relacionarse las empresas con el entorno.

En otras palabras, las organizaciones carboníferas de Colombia y Venezuela, se comportan socialmente responsables con el ambiente, al imperar en ellas una evaluación activa e interactiva entre los colaboradores internos y comunidades del entorno, a objeto de forjar un desarrollo sustentable e imagen bajo una filosofía de gestión donde se encuentren implícitos los parámetros éticos y morales que la sociedad demanda, garantizando con ello la lealtad y compromiso con su entorno, la cual crea el valor agregado a sus productos o servicios, traduciéndose esto en beneficios productivos tanto para sus grupos de interés como para la credibilidad, confianza y reputación en el sector donde se desenvuelven. Se reconoce el hecho que aun hay mucho por hacer, pero se está avanzando al respecto.
Responsabilidad social:

Obligación o sensibilidad social en empresas carboniferas

Según Kliksberg (2004) la responsabilidad social empresarial aumenta la competitividad de la empresa y las compañías que apoyan el trabajo voluntario de su plantel de empleados y tienen mejor productividad porque el personal se identifica más con ellas. Del mismo modo, Soto y Cárdenas (2007) expresan a la responsabilidad social como el compromiso que la organización tiene con la sociedad en donde desarrolla sus actividades, ya sea como institución social, organización económica particular o el conjunto de individuos que la integran.

Por consiguiente, al entender las premisas involucradas en la responsabilidad social, conlleva a estudiar dos términos de interés de acuerdo a lo expuesto por Robbins (2007), en cuanto se refiere a la obligación social y sensibilidad social.

\section{- Obligación social}

De acuerdo a Robbins (2007) una organización al asumir la responsabilidad social ve las cosas distinto y va más allá de lo impuesto por la ley o decide hacerlo por ser lógico desde el punto de vista económico, de este modo lo hace para mejorar la sociedad porque es lo correcto o moralmente correcto.

Por su parte, Guédez (2008) expresa como al vincular la responsabilidad social con la empresa se desprende una respuesta hacia adentro de la misma en lo relativo a la confrontación de las decisiones con la conciencia, es decir la ética, en cambio, la rendición de cuentas remite hacia el cumplimiento de las leyes, normas y costumbres de la realidad social asociandola con la moral. 
En líneas generales, la responsabilidad social en las empresas carboníferas tanto de Colombia como Venezuela, implica no solo una obligación sino además sensibilidad ante el compromiso con su entorno; quizás esta disyuntiva de términos se deba en primer, a la obligación actualmente de las empresas con los diversos rubros integrantes de la economía, los cuales deben mantener su productividad para forjar ventajas competitivas en el mercado, cumpliendo con los índices financieros para garantizar su estabilidad en el mercado, pero también efectuar los compromisos legales.

Es importante destacar lo señalado al respecto por Ostau y Niño (2012) sobre las políticas gubernamentales, las cuales aunque muestran interés por generar una clara responsabilidad social por parte de las empresas, son débiles y no se presentan en forma obligatoria, así, el interés de las empresas proviene más allá de la obligación legal.

\section{- Sensibilidad Social}

Sin embargo, el segundo término referido a la sensibilidad, transciende mas allá de una obligación, asumiéndolo como el compromiso social voluntario, restituyéndole a las comunidades lo extraído de ellas, mediante la planificación y ejecución de actividades sociales que contribuyan a gestar espacios con calidad de vida y bienestar del bien común. De acuerdo a Paz et al. (2015), expresan como esto ayuda a la responsabilidad social a representar la identidad institucional, simbolizando las acciones con rostro humano, otorgandole sensibilidad hacia las situaciones presentes en el entorno.

Dentro de este contexto, se explica que las empresas direccionan sus acciones sociales mediante un aporte voluntario con sentido corresponsable, mediante el apoyo de los grupos de interés para atender las necesidades comunitarias, convirtiendo su funcionalidad social como ente sensible ante las circunstancias acuciantes del entorno, ejerciendo su actividad productiva, sin convertir su aporte en dadivas impuestas por organismos competentes o por presiones políticas; razón por la cual a través de la gestión social compartida, la responsabilidad social le ha facilitado ganar espacios en la proyección de imagen, credibilidad y confianza en el entorno económico donde se desenvuelven.

Por consiguiente, tomando en cuenta los estudios de Moncada (2016), Pertuz (2016) y Daza y Pinedo (2017) se resalta en la actualidad a las empresas carboníferas, porque aun teniendo mucho por hacer, muestran indicios de corresponsabilidad con su entorno, quizás por el cambio de sus esquemas de gestión administrativa tradicional, mostrando un comportamiento consciente de poder contribuir al desarrollo sustentable desde la orientación de sus operaciones de trabajo, empleando procesos con apoyo de tecnologías verdes o bien técnicas y procedimiento que favorezcan estratégicamente el crecimiento económico e incrementar su competitividad, sin traer efectos que deterioren la calidad del ambiente, es decir contribuir a la protección y conservación del medio ambiente, fomentando al mismo tiempo la gestión compartida de acciones de responsabilidad social.

En un mismo modo agregan los resultados del trabajo de Paz et al. (2011), el hecho de como las empresas carboníferas no solo fundan sus bases en pilares económicos, sino también en una sustentabilidad social y ambiental, direccionando sus actividades misionales a incrementar sus capacidades y oportunidades, además del propender el desarrollo de funciones al progreso y bienestar de las generaciones presentes y futuras. 
Las empresas carboníferas en su obrar como modelo de negocio responsable, emprenden desde su gente, un compromiso compartido con la práctica de la gestión social, considerando a la responsabilidad social con su entorno como aporte al desarrollo sustentable generando ventajas competitivas como factor diferenciador en el mercado. En consecuencia, la gestión social forma parte de su plan estratégico, una herramienta administrativa para garantizar la práctica responsable hacia un ambiente sano, empleado desde la operatividad de sus trabajos misionales el enlace voluntario con la comunidad, destacando en su quehacer diario las estrategias corporativas y agregando valor a la competitividad.

Es preciso recordar como los objetivos empresariales de las empresas del sector carbonífero colombianas y venezolanas no son ajenas a los objetivos del milenio, los cuales involucran planes sobre sostenibilidad social, al demandar el bienestar y calidad de vida de la humanidad, por tanto, deben esta insertos en los planes y programas empresariales, como una medida y garantía del bienestar común.

Por ello, en el plan estratégico empresarial, resulta inexcusable, estudiar los múltiples desafíos del sector económico donde se disponen los bienes y servicios centrados en alcanzar niveles de competitividad y productividad, es decir en un nivel económico estable pero al mismo tiempo social, pudiendo desde su patrón corresponsable generar confianza ante su entorno, aunados a colaborar de manera voluntaria para solventar sus necesidades, proponiendo la edificación de una sociedad sustentable dispuesta a progresar por el bienestar del colectivo social.

En este mismo orden de ideas, las empresas colombianas y venezolanas carboníferas, conscientes de las consecuencias generadas en las poblaciones de su medio, deben fomentar la realización de sus actividades asumiendo sus roles, bajo una posición ética y moral, a través de la participación activa del empresario, sus directivos, colaboradores y comunidad, es decir involucrando sus grupos de interés (Pertuz, 2016).

A las empresas carboníferas como entes responsables, se les propende por el bienestar sano, para conjugar progreso y bienestar enmarcado en el principio social y ambiental, modelo de cooperación corresponsable ante la protección del medio ambiente, mediante la implantación de la ecoeficiencia, una filosofía de gestión administrativa coparticipe del lema ecológico, el cual revela bienestar pero también progreso económico, sin dejar de lado el campo humano como factor propulsor de la sensibilidad social ante la calidad de vida en su hábitat.

\section{MÉTODOLOGÍA}

Para el análisis de la situación planteada en el presente artículo, fue necesario obtener información empleando técnicas metodológicas y a partir de ellas, caracterizar un estudio descriptivo (Méndez, 2013 y Hernández, Fernández y Baptista, 2014). Por otro lado, a partir de orientar la situación objeto de estudio, se interpretó como una investigación analítica (Hurtado, 2008) y al mismo tiempo, se tipifica como documental (Arias, 2016, Bernal, 2010 y Tamayo, 2010).

En tal sentido, se emplea la búsqueda de evidencias e información recurriendo a la consulta y revisión de material bibliográfico impreso y electrónico: textos, tesis y trabajos presentados para optar grado, artículos de interés sobre el tema de estudio, planteados en jornadas de investigación y revistas arbitradas, etc; facilitando el desarrollo y discernimiento del marco referencial para cumplir con los aspectos denotados. 


\section{Resultados}

En general, se infiere que las empresas carboníferas colombo-venezolanas, enmarcan la responsabilidad social hacia un desarrollo sustentable, mediante un compromiso ambiental el cual implica la incorporación voluntaria de su gente con la comunidad, estableciendo una plataforma ética compartida entre los grupos de interés, construyendo un perfil empresarial hacia una cultura ambiental donde se apoye la gestión estratégica organizacional, para lograr comunidades sanas corresponsables con el entorno.

También, vale acotar como las acciones empresariales de las empresas carboníferas de Colombia y Venezuela, como parte de su compromiso voluntario hacia el desarrollo sustentable con el entorno, las ha llevado a forjar desde el quehacer de sus funciones misionales espacios de credibilidad, confianza y reputación en el mundo de los negocios, siendo transmisible en sus actividades sociales con las comunidades donde participam, como parte de su planificación estratégica en el quehacer de la dinámica productiva.

En este sentido, la preocupación de las empresas colombianas y venezolanas del sector carbonífero, es construir desde su gestión un patrón de compromiso social en pro de la calidad de vida del tejido social, buscado mecanismos para replantear sus procesos de trabajo conllevándolas al establecimiento de estrategias compartidas con los grupos de interés que las conduzcan a mitigar los efectos contaminantes en las zonas donde ejerce su actividad productiva, aunado al establecimiento de una cultura verde, con uso de técnicas amigables al ambiente. Y aunque se observa que tienen un largo trayecto por recorrer, debe reconocerse su interés en avanzar con respecto al tema, responsabilidad social y desarrollo sustentable, a fin de propender desde sus acciones para aportar a la calidad y bienestar de las personas.

Por otra parte, sus acciones estratégicas sociales y ambientales tienen la responsabilidad de desarrollar tanto formas como modelos de trabajo para enfrentar los retos de la conservación de los sistemas ecológicos, el desarrollo social, cultural y económico, así como su vinculación con los agentes comunitarios para establecer diálogos, en aras de atender sus necesidades acuciantes, mejorando la calidad de vida de la población como parte de compromiso hacia el desarrollo sustentable inmerso en su filosofía de gestión.

En tal sentido, las empresas carboníferas en Colombia y Venezuela, establecen declaraciones sociales y ambientales, desde un papel transparente y activo, generador de diálogos compartidos, en la promoción de conversatorios, foros sobre el tema ambiental y social, debatiendo sobre modelos empresariales, en la búsqueda de mecanismos destinados a mitigar efectos que desgaste la calidad ambiental y el aprovechamiento sustentable para el bienestar social, siendo estos algunas de las alternativas viables para evaluar los problemas, sociales, económicos, educativos y ecológicos a contar. En todo caso para llegar a obtener el desarrollo sustentable deseado, sigue siendo necesario el trabajo en conjunto del sector empresa-gobiernocomunidad.

Si bien es cierto, las empresas carboníferas de estos paises hermanos, desempeñan un rol social esencial en la vida de las comunidades donde estan ejerciendo sus funciones tanto administrativas como operativas, se convierten en líderes sociales ante la búsqueda constante del bienestar colectivo. 
Por otra parte, establecen acciones evaluativas para determinar el impacto que pudiesen generar sus actividades en el ambiente, que podrían repercutir en la degradación del capital natural y con ello la calidad de vida de los habitantes de la zona y sus adyacencias, convirtiéndose en este caso en un agente de desarrollo estratégico en las comunidades en las que están insertas, aunado a ser ente catalizador en la difusión de cambios socioculturales, económicos y sociales enmarcando una gestión ambiental orientada al desarrollo sustentable.

En líneas generales, son múltiples las alternativas valorativas que redimensionan las acciones sociales de las empresas carboníferas de Colombia y Venezuela, para coadyuvar el interés social y ambiental, para lo cual se plantean el compromiso hacia los ejes comunicacionales, a fin de ampliar los medios de difusión entre los grupos de interés, sirviendo tanto al desarrollo como al aprovechamiento sustentable del capital natural, sin degradar o impactar su condiciones $u$ espacios y con ello la calidad del mismo.

Por consiguiente, la generación de sinergias e implementación de un conjunto de estrategias pertinentes en el campo de las empresas carboníferas colombianas y venezolanas buscan contribuir al desarrollo sustentable deseado, mediante la difusión de una actitud responsable hacia el ambiente y la transformación de hábitos empresariales en pro de entornos sanos, es decir reflexionar en procesos justos y legítimos donde su actuación implique la transparencia ética en el desarrollo continuo hacia la mejora de las condiciones ambientales del entorno.

Como puede observarse, aunque diversos estudios revisados muestran el camino que falta por recorrer para la implementación completa de la responsabilidad social empresarial, se observa una orientación de las empresas en el inicio del camino a través de los elementos involucrados con el medio ambiente, y si bien es cierto, existen elementos de mayor peso a tomar en cuenta, el inicio con este aspecto muestra una preocupación genuina de las empresas por generar beneficios a las comunidades locativas. Es necesario ampliar estos estudios para verificar si además del aspecto ambiental se han seguido desarrollando el resto de los elementos de la responsabilidad social.

\section{Conclusiones}

Las empresas carboníferas localizadas en Colombia y el país vecino de Venezuela, como parte de su compromiso deben incorporar en sus estrategias corporativas la responsabilidad social, formando parte de la acción integradora y voluntaria del desarrollo sustentable, ya que no vale solo aportar resultados productivos y económicos a los indicadores de gestión, agregando valor a su estabilidad, sino además deben comportarse con un equilibrio social sano, asentando su gestión en políticas ambientales de aprovechamiento sustentable para preservar la calidad de vida de la gente en las localidades donde coexisten.

Del mismo modo, las empresas carboníferas plantean prácticas para restaurar y mitigar la acción del hombre en sus actividades de trabajo diario sujetas a una gestión empresarial, por ello estas no deben afectar los resultados de los objetivos planificados, pues deben buscar la retribución social de manera integradora con los grupos de interés incorporándolos de forma voluntaria en pro del bien común. 
Como señala Senior, Narváez, Fernández y Revilla (2007) se puede afirmar que la responsabilidad ambiental de las empresas aparece como un concepto innovador y necesario en este milenio, el cual está enmarcado en el contexto de la globalización y la transformación del rol del estado y la participación ciudadana en asuntos de interés común.

En líneas generales, el éxito de las actividades empresariales del sector carbonífero de Colombia y Venezuela, se traduce en la interrelación con los grupos de interés enlazando la participación del capital humano como eje motor en la generación de ideas y alternativas viables para fomentar la responsabilidad social y ambiental, y con ello la sustentabilidad. En todo caso, se proyecta más que una obligación gubernamental impositiva como una organización sensible comprometida con la sociedad, ejerciendo de forma corresponsable la construcción del desarrollo sustentable desde los principios éticos asentados en su razón de ser, los cuales suscribe en un marco de acción hacia el bien común.

\section{REFERENCIAS}

Añez, S., Hernández, R., Silvestri, K. y Gómez, O. (2008). Análisis de los elementos que componen la responsabilidad social corporativa. Formación Gerencial, 7(2). 173-185.

Arias, F. (2016). El Proyecto de Investigación. ( $7^{\circ}$ ed.). Caracas: Episteme.

Bernal, C. (2010). Metodología de la Investigación para la Administración y Economía, Humanidades y Ciencias Sociales. México, D.F.: Pearson Educación

Blanco-Uribe, A. (2005). La definición del derecho-deber individual y colectivo al ambiente en derecho comparado. Caracas: Tribunal Supremo de Justicia.
Castro, A., Hernández, J. y Bedoya, E. (2016). Caracterización de las dimensiones de la responsabilidad social corporativa en la empresa hotelera almirante. Cartagena. Saber, Ciencia y Libertad, 11(2). 177-188.

Chiavenato, I. (2017). Administración de recursos humanos. El capital humano de las organizaciones. $\left(10^{\circ}\right.$ ed.) México, D.F.: Mac Graw Hill.

Chumaceiro, A. y Hernández, J. (2016). Países generadores de políticas públicas para el fomento de la cultura empresarial dirigida hacia la responsabilidad social. Revista Telos, 18(1). 103-120. Disponible en http:// ojs.urbe.edu/index.php/telos/article/ view/790

Chumaceiro, A., Hernández, J. y Chirinos, E. (2016). Responsabilidad social universitaria, desarrollo sostenible y ciudadanía ambiental. Cuadernos de RSO. 4(1). 53-64.

Claros, O. (2001). Control Fiscal y Medio Ambiente. Bogotá, D.C.: Ecoe.

Daza, L. y Pinedo, X. (2017). Análisis de la Política de Responsabilidad Social Empresarial del Cerrejón con la Comunidad Wayúu (20142016) (Trabajo de Pregrado). Universidad de la Salle, Bogotá, D.C. Recuperado de http://repository. lasalle.edu.co/bitstream/handle/10185/20910/64111032 2017. pdf? sequence $=1 \&$ isAllowed $=y$

Gardetti, M. (2004). Creando valor sustentable. Bussiness \& Sustainability Letter, 1(2). 114-126.

Garmendia, A., Salvador, A., Crespo, C. y Garmendia, L. (2010). Evaluación de Impacto Ambiental. Madrid: Pearson-Prentice Hall.

Guédez, V. (2008). Ser Confiable. Responsabilidad Social y Reputación Empresarial. Caracas: Planeta Venezolana. 
Harris, J., Paz, A. y Franco, F. (2014). Compromiso organizacional: Estímulo del éxito del personal docente en las universidades privadas. Económicas CUC, 35(1). 91-106.

Hernández, R., Fernández, C. y Baptista; M. (2014). Metodología de la Investigación. (6 ${ }^{\circ}$ ed.). México, D.F.: Mc. Graw Hill Interamericana.

Hurtado, J. (2008). Metodología de la Investigación. Caracas: Fundación Sypal.

Kliksberg, B. (2004). Responsabilidad Social Empresarial en las Américas. Caracas: Editorial Fondo Cultural del Centro Internacional de Educación y Desarrollo.

Méndez, C. (2013). Metodología Diseño y Desarrollo del Proceso de Investigación. (4ed.). Bogotá, D.C.: Limusa.

Mendoza-Fernández, D., Salas-Solano, E. y López-Juvinao. D. (2015). Responsabilidad social en Universidades Públicas Autónomas: Esencia académica con visión transformadora. Clio América, 9(18), 135-142. http://dx.doi. org/10.21676/23897848.1531

Moncada, N. (2016). La responsabilidad social en el sector minero en Colombia (Trabajo de Especialización). Universidad Militar Nueva Granada, Bogotá, D.C. Recuperado de https://repository.unimilitar.edu.co/bitstream/ handle/10654/15679/MoncadaTorresNataly2016.pdf;jsessionid=05805E3D 6AA3345331A3CE7FE0FA6B88?seq uence $=1$

Ostau, F. y Niño, L. (2012). La responsabilidad social empresarial en las empresas del sector carbonífero colombiano: Lecciones y experiencias de las transnacionales mineras en el marco de los estándares internacionales determinados por la Organización Internacional del Trabajo. Dialogo de Saberes, 36(1). 81-98. Recuperado de_https:// revistas.unilibre.edu.co/index.php/ dialogos/article/view/1852
Paz, A., Paz, E. y Paz, J. (2011). Responsabilidad social: un desafió u obligación ante la gestión ambiental en empresas carboníferas. En, III Jornadas Científicas Internas "Dr. José Gregorio Hernández". Universidad Dr. José Gregorio Hernández, Maracaibo, Venezuela.

Paz, A., Harris, J. y Paz, J. (2015). Cultura ética y responsabilidad social: identidad con rostro humano en universidades. En, El desarrollo de un pais depende de la ciencia. Dr. Jacinto Convit. VII Jornadas Científicas Nacionales Dr. José Gregorio Hernández, Maracaibo, Venezuela.

Paz, A., Harris, J. y Franco, F. (2016). Responsabilidad social gestión compartida con el emprendedor social en empresas mixtas del sector petrolero. Económicas CUC, 37(2). 47-68. http://dx.doi.org/10.17981/ econcuc.37.2.2016.03

Paz, A., Núñez, M., Salom, J. y Rosales, V. (2013). Responsabilidad social universitaria: moralidad o compromiso en la formación de valores éticos en la educación de futuro. Revista Opción, 29(72). 97-116

Pertuz, A. (2016). La práctica de la responsabilidad social empresarial en la minería Latinoamericana. Revista Pensamiento Gerencial, 4(1). 1-22. Recuperado de https://revistas.unisucre.edu.co/index.php/rpg/ article/download/538/609/

Pizzolante, I. (2010). Modelo de fortalecimiento institucional para la comunicación estratégica en empresas socialmente responsable. Comunicación: estudios venezolanos de comunicación, 152(4). 2026.

Robbins, S. (2007). Administración. (8º ed.) México D.F.: Pearson Educación. 
Senior, A., Narváez, M., Fernández, G. y Revilla, J. (2007). Responsabilidad ambiental: factor creador de valor agregado en las organizaciones. Revista de Ciencias Sociales (Ve), 13(3). 484-494. Recuperado de www. redalyc.org/service/redalyc/downloadPdf/280/28011681009/1

Solano, M. (2014). ¿Es posible una minería con responsabilidad social empresarial? Acercamiento al municipio de Tausa-Cundinamarca. CriteriosCuadernos de Ciencias Jurídicas y Política Internacional, 7(1). 19-46.

Soto, E. y Cárdenas, J. (2007). Ética en las Organizaciones. México, D.F.: McGraw-Hill/Interamericana.

Tamayo, M. (2010). El Proceso de la Investigación Científica. ( $7^{\circ}$ ed.) México, D.F.: Limusa. D.F.

\section{Biodata}

Leandro Amiro Sierra Daza es Director-Fundador de la Fundación Escuela de Minería de La Guajira (2004). Actual. candidato a PostDoctor en Gerencia en las Organizaciones, Doctor en Ciencias Gerenciales con MSc. en Gerencia de Recursos Humanos de la Universidad Rafael Belloso Chacín (Venezuela) y MSc. em Gerencia Empresarial de la Universidad Rafael Belloso Chacín (Venezuela), Ingeniero de Minas de la Fundación Andina. https://orcid. org/0000-0002-0565-1203

Annherys Isabel Paz Marcano es Doctora en Ciencias Gerenciales de la Universidad Rafael Belloso Chacín (Venezuela) con Magister en Gerencias de Recursos Humanos de la Universidad Rafael Belloso Chacín (Venezuela) y Administradora de Empresas de la Universidad Rafael Belloso Chacín (Venezuela). Profesora e Investigadora de la Universidad de la Guajira. https://orcid.org/0000-0001-7538-1563

Danny Daniel Lopez Juvinao es Doctor en Ciencias Gerenciales de la Universidad Rafael Belloso Chacín (Venezuela) con MSc. en Gerencia Empresarial de la Universidad Rafael Belloso Chacín (Venezuela) e Ingeniero en Minas de la Universidad pedagógica y tecnológica (Colombia). Profesor de la Universidad de La Guajira (Colombia). http://orcid.org/0000-00029304-1105 